\title{
Surface plasmon resonance: principles, methods and applications in biomedical sciences
}

\author{
Patrick Englebienne*, Anne Van Hoonacker and Michel Verhas \\ Free University of Brussels, Department of Nuclear Medicine, Brugmann University Hospital, \\ Place van Gehuchten 4, B-1020 Brussels, Belgium
}

\begin{abstract}
Surface plasmon resonance (SPR) is a phenomenon occuring at metal surfaces (typically gold and silver) when an incident light beam strikes the surface at a particular angle. Depending on the thickness of a molecular layer at the metal surface, the SPR phenomenon results in a graded reduction in intensity of the reflected light. Biomedical applications take advantage of the exquisite sensitivity of SPR to the refractive index of the medium next to the metal surface, which makes it possible to measure accurately the adsorption of molecules on the metal surface and their eventual interactions with specific ligands. The last ten years have seen a tremendous development of SPR use in biomedical applications. The technique is applied not only to the measurement in real-time of the kinetics of ligand-receptor interactions and to the screening of lead compounds in the pharmaceutical industry, but also to the measurement of DNA hybridization, enzyme-substrate interactions, in polyclonal antibody characterization, epitope mapping, protein conformation studies and label-free immunoassays. Conventional SPR is applied in specialized biosensing instruments. These instruments use expensive sensor chips of limited reuse capacity and require complex chemistry for ligand or protein immobilization. Our laboratory has successfully applied SPR with colloidal gold particles in buffered solution. This application offers many advantages over conventional SPR. The support is cheap, easily synthesized, and can be coated with various proteins or protein-ligand complexes by charge adsorption. With colloidal gold, the SPR phenomenon can be monitored in any UV-vis spectrophotometer. For high-throughput applications, we have adapted the technology in an automated clinical chemistry analyzer. This simple technology finds application in label-free quantitative immunoassay techniques for proteins and small analytes, in conformational studies with proteins as well as in the real-time association-dissociation measurements of receptor-ligand interactions, for high-throughput screening and lead optimization.
\end{abstract}

\section{Introduction}

Surface plasmon resonance (SPR) was introduced in the early 1990s as the underlying technology in affinity biosensors for biomolecular interaction analysis (BIA), a new concept for the analysis of the functional properties of biomolecules [1]. The affinity biosensor technology filled the need for more meaningful information on biomolecular interactions than what could be gained from classical endpoint immune- or receptor-binding assays [2]. BIA with biosensors allowed a real-time follow-up of the kinetics of interaction between a pair of biomolecules in absence of any tracer [1]. This was made possible by immobilizing one of the partner of the pair on a metal surface, allowing the other partner to flow in excess over that surface, whilst using SPR spectroscopy to measure the changes in refractive index occuring at the metal surface upon interaction between the two biospecific partners. Such an approach for studying biomolecular interactions finds its place in a set of strategies intended to use so-called 'intelligent' reporter systems to study biomolecular interactions that our laboratory is keen to investigate for some time $[2,3]$.

\footnotetext{
*Corresponding author. E-mail: penglebi@ulb.ac.be.
} 
Whilst several biosensor concepts have been developed [2,4,5], affinity biosensors using SPR have the merit to be the first sensor instruments and systems to be commercialized and hence made available to thousands of laboratories. However, affinity biosensors present several drawbacks, of which the least is most probably not the cost of instrument and sensor chips. Besides that, SPR biosensors usually lack the sensitivity to detect the interaction of proteins with small ligands [6] and due to their inability to handle many samples simultaneously, they are unsuitable for use in high throughput applications [7]. Therefore, our laboratory has considered for some time to use the SPR technology with colloidal gold particles as the spectroscopic substrate instead of the gold metal layers used in conventional biosensors [8]. We were made confident in our hypothesis that SPR could work with colloidal gold by a report showing that the combination of a gold metal layer with colloidal gold particles in an affinity biosensor chip resulted in a tremendous increase in sensitivity [9]. Such an application of SPR presents the advantage of being accessible to many laboratories because it requires only cheap reagents and an UV-vis. spectrophotometer. Meanwhile, other laboratories have adopted the same strategy with success, using either, like us, colloidal particles in suspension [10,11], or a layer of colloidal gold particles on a glass plate [12], respectively. In this article, we review the theory of SPR spectroscopy in both conventional affinity biosensors and colloidal metal configurations, we present the various approaches to immobilize proteins on the sensor substrates and exemplify our approach with colloidal gold with several applications.

\section{Conventional surface plasmon resonance}

Conventional SPR measurements as applied in biosensors are used to monitor the changes in thickness or refractive index of ultrathin organic films at metal surfaces [13]. The SPR phenomenon occurs when an incident beam of p-polarized light of a given wavelength strikes the surface at a given angle through a prism. In such conditions, photon-plasmon surface electromagnetic waves (surface plasmon polaritons) are created at the metal/dielectric interface. These waves propagate parallel to the metal dielectric interface and the associated optical electric field decays exponentially away from the surface with a typical decay length of $200 \mathrm{~nm}$ [13]. This results in a reduced intensity of the reflected light at this angle. The reflectance of the incident light at a given angle $\theta$ can be calculated using a three-layer Fresnel equation relating p-polarization [14], in which the sensing system consists of three media $j$, a glass prism-metallic film-sensing layer, denoted respectively by $\gamma, \mu$ and $\rho$ subscripts. The reflectance $R$ of the incident light is calculated as follows:

$$
\begin{aligned}
& R=\left|\frac{r_{\gamma \mu}+r_{\mu \rho} \mathrm{e}^{2 \mathrm{i} k_{\mu} d}}{1+r_{\gamma \mu} r_{\mu \rho} \mathrm{e}^{2 \mathrm{i} k_{\mu} d}}\right|^{2} \\
& \quad \text { with } k_{j}=\sqrt{\varepsilon_{j} \frac{\omega^{2}}{c^{2}}-k_{z}^{2}} \text { for } j=\gamma, \mu, \rho \text { and } k_{z}=\sqrt{\varepsilon_{\gamma}} \frac{\omega}{c} \sin \theta,
\end{aligned}
$$

and the amplitude reflectance for prism-metal and metal-sensing layer interfaces are given by the following equations:

$$
r_{\gamma \mu}=\frac{k_{\gamma} \varepsilon_{\mu}-k_{\mu} \varepsilon_{\gamma}}{k_{\gamma} \varepsilon_{\mu}+k_{\mu} \varepsilon_{\gamma}}, \quad r_{\mu \rho}=\frac{k_{\mu} \varepsilon_{\rho}-k_{\rho} \varepsilon_{\mu}}{k_{\mu} \varepsilon_{\rho}+k_{\rho} \varepsilon_{\mu}},
$$




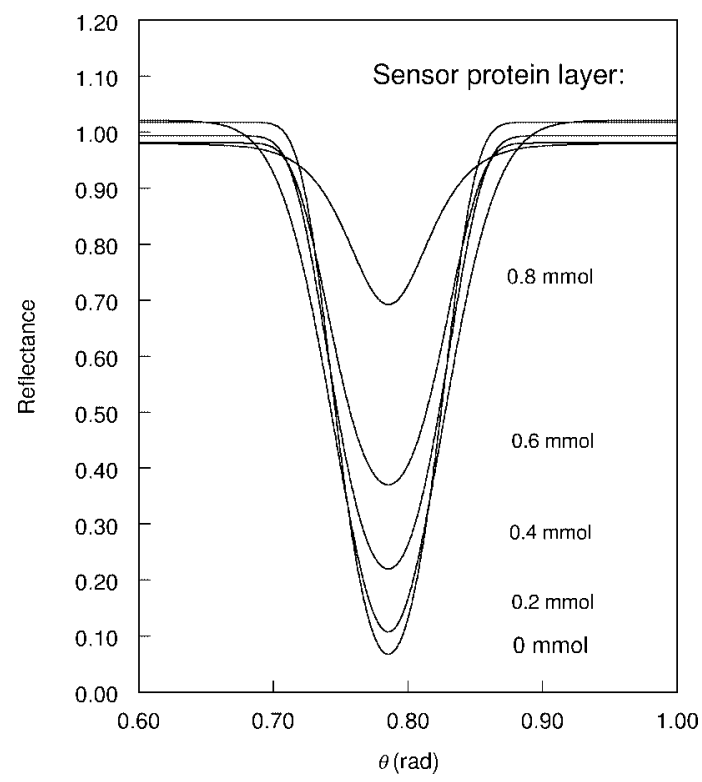

Fig. 1. Evolution of SPR spectra simulated for increasing ligand protein concentrations, calculated according to the Fresnel three layer model given in Eq. (1), for a light beam $(\lambda 600 \mathrm{~nm})$ striking the metal and sensing layers through a glass prism at an angle $\theta$ of $45^{\circ}$ (0.785 radians).

where $\varepsilon_{j}$ and $k_{j}$ are the dielectric constant and the wave-vector component perpendicular to the interface in the respective medium $j$ (prism, metal or sensing layer), $k_{z}$ is the component of the incident wave vector parallel to the interface, $\omega$ is the angular frequency of the incident light $(\omega(\lambda)=2 \pi c / \lambda), d$ is the thickness of the metallic film and $c$ is the velocity of light. According to the set of Eqs (1) and (2), the reflectance varies as a function of the dielectric constant $\varepsilon_{\rho}$ of the sensing layer [14], which is the square of the refractive index and consists of $N$ absorption oscillators per unit of volume that depend on the ligand concentration on the layer surface. The application of this mathematical model allows to simulate the SPR spectra displayed in Fig. 1. In conventional SPR biosensors, like the BIAcore instrument, monochromatic light with a broad distribution of incident angles is used and the reflected light reach the detector at different points [15,16], depending on the angle of reflection. The detector continuously records the position of reduced light intensity and calculates the SPR angle of reflected light. This increases the sensitivity of the detection system. The change in SPR angle $\theta$ of reflected light at a given wavelength is directly related by constants $c_{1}$ and $c_{2}$ to both the change in refractive index $n$ at the surface and the change in thickness $d$ of the layer, according to the relationship [17-20]

$$
\Delta \theta(\lambda)=c_{1} \Delta n+c_{2} \Delta d
$$

in which relationship (3), any change in protein thickness $(\Delta d)$ by i.a. a conformational change of the protein or a binding event will predict a refractive index change $(\Delta n)$ according to the Lorentz-Lorenz relation [17]:

$$
\Delta n=-\frac{1}{6 n}\left(n^{2}+2\right)^{2}\left(\frac{n^{2}-1}{n^{2}+2}-\frac{n_{w}^{2}-1}{n_{w}^{2}+2} \frac{V_{p}}{V}\right) \frac{\Delta d}{d},
$$




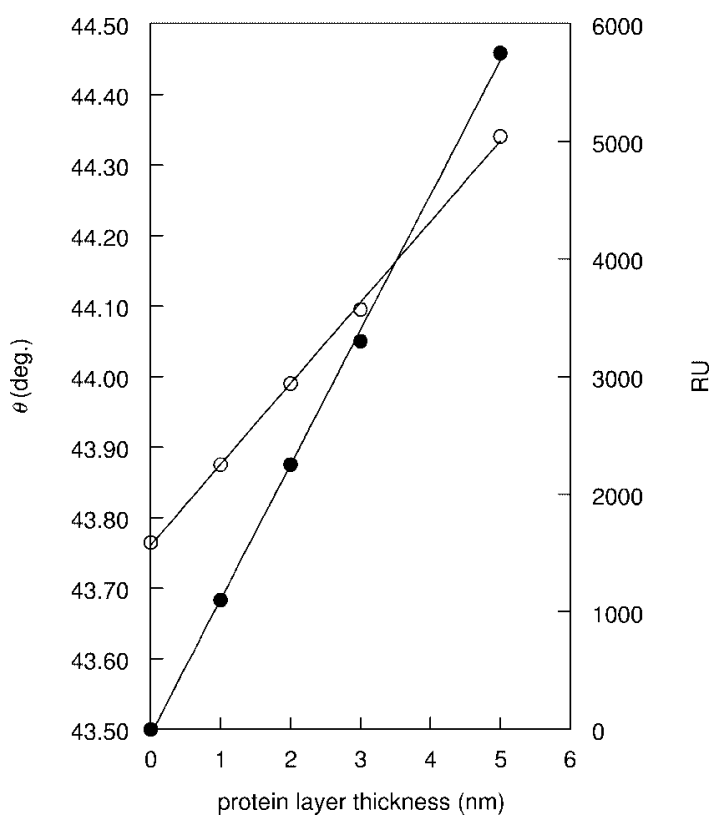

Fig. 2. Evolution of the SPR angle of reflected light (open circles) and the corresponding resonance units (RU, closed circles) in a conventional biosensing instrument as a function of the thickness of the protein layer on the gold surface.

where $n$ is the refractive index of the protein, $n_{w}$ is the refractive index of water, $V_{p}$ is the volume of the protein and $V$ the volume of the protein layer $\left(V=V_{p}+V_{w}\right)$.

The SPR angle change is reported as resonance units (RU). A response of $10^{3} \mathrm{RU}$ corresponds to an angle change of 0.1 degree which is produced for most proteins by the binding on the sensing layer of approximately $1 \mathrm{ng} / \mathrm{mm}^{2}$ [16]. The theoretical angle change can be calculated [13] using complex Fresnel equations. The plot of Fig. 2 shows the change in reflected SPR angle $\theta$ and the corresponding RU response which occurs when the thickness of a protein layer increases up to $5 \mathrm{~nm}$ over a $50 \mathrm{~nm}$ gold layer. As can be noted, the relationships are linear [21]. Thus, the instrument is capable of monitoring in-real time the evolution of both the thickness and the refractive index, the changes of which are the consequence of the biomolecular interactions occurring at the sensing gold layer.

In a conventional SPR instrument, the biomolecular interaction occurs on a sensor chip made of a glass plate on which a thin layer of metallic gold (usually $50 \mathrm{~nm}$ thick) is coated. The protein to be studied is immobilised on this gold surface. During the real-time studies, buffer flows over the sensor chip and therefore, any desorption of the protein layer due to the flow must be avoided. Consequently, physical adsorption of the protein is probably not the best alternative. Although it is possible to adsorb directly proteins to the gold surface through thiolate bonds [22], a prerequisite is that the protein contains available sulfhydryl groups. This is possible with antibody Fab'-SH fragments [22] but not with any protein. Alternatively, the gold surface may be modified with alkanethiolates containing carboxylic groups for further covalent attachment of proteins or peptides $[23,24]$ or modified DNA $[25,26]$ through amide or thiol bonds. However, the most classical approach consists in linking a $100 \mathrm{~nm}$ thick layer of carboxymethylated dextran to the gold surface derivatized with 16-mercaptohexadecan-1-ol [27]. Proteins are then covalently attached directly to the modified dextran, or bound through a streptavidin-biotin bridge $[25,28,29]$. 


\section{Biomedical applications of SPR with biosensors}

The most common application of biosensing SPR instruments is the determination of affinity parameters for biomolecular interactions [30]. The ligand or the binding protein is immobilized on the sensor chip and its binding partner is added to the buffer flowing over the chip. The concentration of the binding partner in the buffer is constant, which favors association. When equilibrium is reached, the flow is switched to buffer devoid of any interacting molecule. This disrupts the equilibrium and dissociation of the bound partner occurs. The process is repeated with several concentrations of binding partner in the buffer, after that the sensor chip is regenerated by washing steps intended to remove any analyte bound on the binding partner immobilized on the chip [31]. The instrument reports the changes in RU occurring during association and dissociation in a sensorgram as exemplified in Fig. 3. An appropriate treatment of the data allows to infer the association and dissociation constants and hence the affinity constant of the interaction [2,28]. The technique presents several advantages over conventional methods of affinity measurements [30]. It requires little material, is very fast and does not need any labeling with a tracer. A major drawback is the need to regenerate the sensor chip for measurements with various concentrations. Several approaches have been proposed to counter this problem, including the use of multichannel instrument [32] and in single channel instruments, of a gradient of analyte concentration in the buffer flow [33]. The application of conventional SPR to affinity measurements has found a place in many areas of biomedical sciences. Typical examples of applications are summarized in Table 1. However, as mentioned above [17-20], SPR measurements are not only sensitive to changes in the refractive index of the medium surrounding the sensor, but also to the thickness of the sensor layer. As any change in protein conformation will bring a modification in this parameter, SPR has also been extensively used to study the conformation of immobilized proteins in various environments [17,18,51,52].

The most recent developments of conventional SPR are in the growing field of proteomics in combination with matrix-assisted laser desorption/ionization time of flight mass spectrometry (MALDI-TOF). In the combination of these two techniques, SPR allows to study biomolecular interactions between mole-

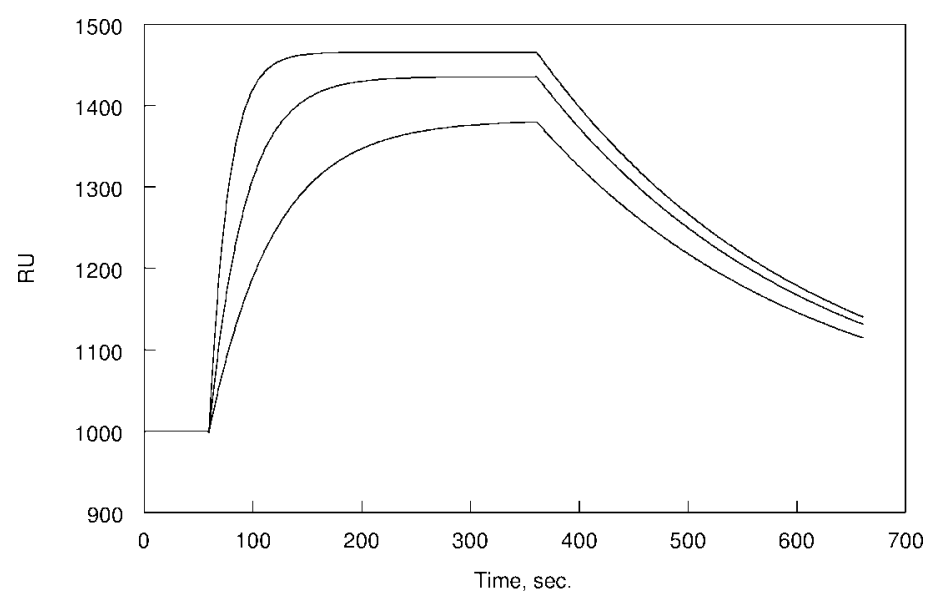

Fig. 3. Sensorgram showing the evolution of resonance units (RU) versus time during association and dissociation measurements performed in the BIAcore instrument. The binding partner immobilized on the chip is a monoclonal anti-human chorionic gonadotrophin (hCG) antibody (M2F05, OEM Concepts, Toms River, NJ) and the association is measured in presence of increasing concentrations of hCG, respectively 13,27 and $54 \mathrm{nM}$. A delay of $60 \mathrm{sec}$ is applied before the analyte is added to the buffer and the association is allowed to occur during $300 \mathrm{sec}$ before the flow is switched to analyte-free buffer for dissociation measurements. 
Table 1

Examples of applications of affinity measurements by conventional SPR with biosensors in biomedical sciences

\begin{tabular}{ll}
\hline Applications & References \\
\hline Nuclear receptor-DNA interaction & {$[34]$} \\
Immunoreactivity of antibody conjugates & {$[35]$} \\
Peptide-antibody interactions & {$[36]$} \\
Enzymatic turnover & {$[37]$} \\
DNA hybridization & {$[25,26]$} \\
Detection of polymerase chain reaction products & {$[38]$} \\
Characterization of proteins by epitope mapping with monoclonal antibodies & {$[39]$} \\
Quantitative immunoassays & {$[40-42]$} \\
Quantitative receptor assays & {$[43]$} \\
Drug absorption extrapolation & {$[44]$} \\
Drug-protein interactions & {$[45]$} \\
Analysis of structure-function relationship of proteins and ligands & {$[46]$} \\
Analysis of antibody-antigen interactions & {$[47-49]$} \\
Quantitative structure-activity relationship (QSAR) & {$[50]$} \\
\hline
\end{tabular}

cules of which at least one is known (attached to the sensor layer). If a mixture of proteins is used during the interaction study, the interacting molecule is not necessarily identified. Therefore, MALDI-TOF allows to identify the molecule(s) from the mixture that interact with the sensor [53,54]. The combination is very efficient because the metal layer concurs in the laser desorption/ionization process [55]. The direct application of MALDI-TOF on the sensor chip is however destructive. Therefore, recent developments have applied new anchoring sample supports for the MALDI-TOF procedure [56,57] that allow the elution and capture of the binding partner(s) from the SPR instrument for further identification [58]. This permits the regeneration of the sensor chip.

The continuous development of SPR applications in biomedical sciences during the last decade enlightens the many promises of the technique [59]. More recently, a new prospect was further opened to SPR with its application in the biophysical characterization of binding and structural events occurring in biomembranes, allowing for a deeper and dynamic understanding of the specific and non-specific interactions occurring at the cell surface [60].

\section{Surface plasmon resonance with colloidal gold in solution}

Despite a quite high popularity and broad availability in laboratories, SPR biosensors are not devoid of disadvantages. The major drawback is the sensitivity of the system with a detection limit restricted at $1-10 \mathrm{nM}$ of a $20-\mathrm{kDa}$ protein [61] and even higher for smaller molecules [6], particularly when the receptor displays a weak affinity $[45,62,63]$. Several strategies were proposed in order to circumvent this drawback. The use of liposomes sensitized with biotin has been proposed, which interact with an avidin-labeled second antibody and increase the specific mass at the sensor surface [61]. Another approach consisted in monitoring the conformational changes of the immobilized receptor upon interaction with small ligands [64]. Finally, colloidal gold was incorporated with success in biosensors resulting in an increased sensitivity of ligand-protein [9] and DNA-DNA interactions [65]. The change in SPR angle magnitude was further shown to be particle-size dependent up to $45 \mathrm{~nm}$ in diameter [66]. The phenomenon has been attributed to a perturbation of the propagation of the surface plasmon polaritons on the metal layer by the localized surface plasmon of the particles [67]. A second, minor disadvantage 
of SPR biosensors results from the absolute requirement to immobilize proteins on the sensor through a covalent linkage in order to avoid desorption by the buffer flowing over the sensor surface. In most configurations, a layer of carboxymethylated dextran is used as the interface allowing for protein immobilization on the gold surface. This $100 \mathrm{~nm}$ thick interface has been held responsible for mass-transfer resistance and for inducing steric hindrance during the biomolecular interactions that take part at the sensor surface, resulting in the underestimation of the affinity parameters when compared to classical determinations in solution [68,69]. Finally, although multichannel biosensing instruments [32] and imaging array system $[25,70]$ have been developed to monitor ligand-protein and DNA hybridization with DNA or RNA respectively, these sytems remain too slow for an application in high throughput screening [7]. These limitations led our group to consider colloidal gold nanoparticles in suspension as a possible and attractive configuration to carry out SPR measurements with an UV-vis spectrophotometer, a system of which we showed the feasibility as early as 1998 [8].

When noble metal nearly monodisperse spherical nanoparticles in solution are excited by electromagnetic radiation, they exhibit collective oscillations of their conduction electrons that result in wavelengthselective absorption and scattering of the incident radiation. With colloidal gold nanoparticles, this excitation results in an extinction spectrum exhibiting a single peak around $520 \mathrm{~nm}$ known as the localized surface plasmon resonance (LSPR) [71]. Thanks to Gustav Mie's work, it has been known for close to a century that the various colors that colloidal gold solutions can display (and hence the shifts of the LSPR) are dependent on the particle size and shape [72,73]. In the early eighties, this property of colloidal gold solutions to display changes in the visible spectrum was extensively applied by a research team of Organon in the development of sandwich immunoassays [74-78]. The change in size and shape of antibody-gold nanoparticles conjugates occurring when their agglutination was induced by the presence of the antigen resulted in a dose-dependent decrease in extinction of the LSPR of the gold colloid. This new immunoassay method showed promise since the technique was homogeneous, i.e., did not need a separation of the free antigen from bound complexes [3]. Unfortunately, the LSPR effect proved very sensitive to non-specific interactions and was barely applicable to crude serum or urine samples [79]. However when a suitable separation of the possible interfering components in the sample could be effected, the technique proved useful as shown later by its application to the determination of the affinity of monoclonal antibodies [80]. The technique is also applicable to the study of oligonucleotide hybridization in buffered solutions [81,82]. Our understanding of the direct LSPR effect on individual gold nanoparticles [8] described below as an additive phenomenon to the agglutination LSPR signal, allowed recently our laboratory to avoid the non-specific interactions with crude biological human samples and to design a quantitative homogeneous agglutination immunoassay with colloidal gold [83].

Besides the effects of size and shape on the LSPR of noble metal colloids which were demonstrated for a while [72,73], the effect of changes in the refractive index of the surrounding medium was more difficult to appreciate at an experimental point of view because of the very high susceptibility of the nanoparticles to flocculate in organic solvents. The direct effect of the refractive index of the surrounding medium was actually demonstrated with gold colloids in 1994 [84], with gold and silver colloids in 1995 [85] and confirmed more recently with silver nanoparticles [86-88].

Gold spherical nanoparticles obey the physical laws of any particle of a size smaller than that of the incident light [89] and therefore, their extinction at a given wavelength $E(\lambda)$ is the sum of absorbance $A$ and scattering $S$ for a given optical pathlength $L_{t}$, according to the relationship:

$$
E(\lambda) L_{t}=S(\lambda)+A(\lambda) L_{t} .
$$


The Mie scattering treatment for metal particles allows to relate the extinction term of Eq. (5) to the refractive index of the surrounding medium by a tedious expansion of complex series of scattering coefficients that describe the amplitudes of the scattered and magnetic fields [73,89]. The Maxwell-Garnett approach is easier to handle [73], which assumes that it is reasonable to define an effective complex dielectric constant $\varepsilon_{m}$ for the metal particles and a complex dielectric constant $\varepsilon_{0}$ for the medium that surrounds them. These constants are related to the particle polarizability $\alpha(\nu)$ by the Lorentz-Lorenz relation $[10,73]$ :

$$
\alpha(\nu)=f_{m}\left(\frac{\varepsilon_{m}-\varepsilon_{0}}{\varepsilon_{m}+\kappa \varepsilon_{0}}\right),
$$

where $f_{m}$ is the volume fraction of the metal in the mixture and $\kappa$ is the screening parameter depending on the geometry of the metal inclusions ( $\kappa=2$ for spheres and tends to unity for needles oriented with their axes of revolution parallel to the direction of incident light). The complex dielectric constant of the metal $\varepsilon_{m}$ can be calculated by assuming a Drude model as:

$$
\varepsilon_{m}=\varepsilon_{m}^{\infty}-\frac{\omega_{p}^{2}}{\omega\left(\omega+i \omega_{\tau}\right)}=\varepsilon_{m}^{\prime}+i \varepsilon_{m}^{\prime \prime},
$$

where $\varepsilon_{m}^{\infty}$ is the dielectric constant contribution from bound electrons, $\omega_{p}$ is the plasmon frequency and $\omega_{\tau}$ the damping frequency of the bulk metal, and $\omega$ the angular frequency of the incident light as defined above for Eq. (1). According to Eq. (7), the complex dielectric constant can further be decomposed into its real and imaginary components $\varepsilon_{m}^{\prime}$ and $\varepsilon_{m}^{\prime \prime}$, respectively. The optical extinction cross section $C_{E(\lambda)}$ for a single particle is related to the particle polarizability $\alpha(\nu)$ via its absorbance and scattering cross sections as follows $[10,85]$ :

$$
C_{E(\lambda)}=k \mathrm{i} \alpha(\nu)+\frac{k^{4}}{6 \pi}|\alpha(\nu)|^{2},
$$

where

$$
k=\frac{2 \pi r \sqrt{\varepsilon_{0}}}{\lambda}
$$

in which $r$ is the particle radius.

Finally, the transmittance $T$ is related to the extinction cross-section $[10,73]$ by the following relationship:

$$
T=\mathrm{e}^{-N C_{E(\lambda)} L_{t}},
$$

where $N$ is the number density of particles.

In the case of noble metals, as exemplified for gold in Fig. 4, solving Eq. (7) in the visible region of the spectrum shows that the imaginary part of the complex dielectric constant $\varepsilon_{m}$ is small and does not vary with $\lambda$, counter to the real part which is negative and decreases monotonically with $\lambda$. Therefore, according to Eqs (6) and (7), if we consider only the real part of $\varepsilon_{m}$ and $\varepsilon_{0}, \alpha(\nu)$ and hence $C_{E(\lambda)}$ will become very large when $\varepsilon_{m}^{\prime}+\kappa \varepsilon_{0}^{\prime} \rightarrow 0$, i.e., at the wavelength corresponding to the LSPR of the colloidal 


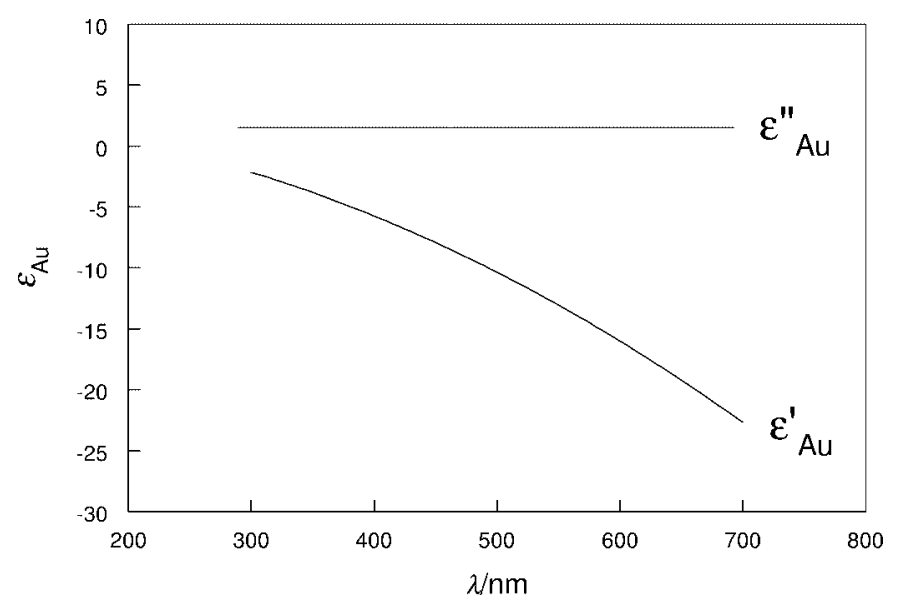

Fig. 4. Evolution of the imaginary $\left(\varepsilon_{m}^{\prime \prime}\right)$ and real $\left(\varepsilon_{m}^{\prime}\right)$ parts of the complex dielectric constant of Au in the visible part of the spectrum as a function of the wavelength of the incident light $(\lambda)$, calculated according to Eq. (7).

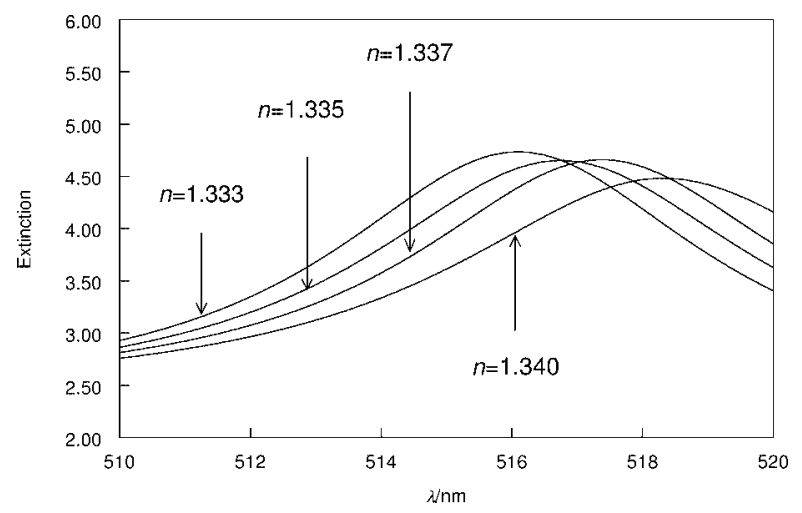

Fig. 5. Spectra of $50 \mathrm{~nm}$ diameter spherical colloidal gold particles in solution, simulated according to Eqs (7) and (8). The refractive index $(n)$ of the surrounding medium was varied from 1.333 (water) to 1.340. The LSPR of the colloid is red-shifted by approximately $1 \mathrm{~nm}$ for a 0.02 unit change in $n$.

metal $[10,86]$. As a consequence, any tiny change in the complex dielectric constant and hence in the refractive index $\left(n_{0}=\sqrt{\varepsilon_{0}}\right)$ of the surrounding medium will change the wavelength of the LSPR. This is exemplified in Fig. 5 with colloidal gold spectra simulated by solving Eqs (5)-(10). This principle is applied in the SPR measurements with colloidal gold.

\section{Biomedical applications of SPR with colloidal gold}

Colloidal gold spherical nanoparticles are quite easy to synthesize by reduction of a boiling aqueous solution of hydrogen tetrachloroaurate with sodium citrate and the citrate/gold molar ratio allows to finetune the size of the particles $[2,3,8]$. With this synthetic method, the colloidal gold solutions are relatively homeodisperse according to our's and others' experience $[2,89]$. So far, we have obtained the best results in our applications of SPR with colloidal gold by using particles of $50 \mathrm{~nm}$ in diameter. Colloidal gold nanoparticles remain negatively charged over a wide range of $\mathrm{pH}$ values [90] and consequently, proteins 
are easily coated on the surface by charge adsorption at $\mathrm{pH}$ values close to or slightly above the isoelectric point [91,92]. Because the particles remain in suspension during the experiments and are not submitted to additional external physical forces, this type of protein immobilization is acceptable. We use to coat colloidal gold with a protein concentration just sufficient to stabilize the particles from coagulation by salts, in order to prevent as much as possible the formation of multiple layers $[2,3,8]$. The verification of the effect of $\mathrm{pH}$ during coating on the activity of the protein is also of prime importance since it has been shown that changes in protein conformation may alter the activity [92,93]. When we perform $\mathrm{pH}$ titration isotherms, we check the protein activity in addition to the colloid stability [2,3], so as to have at hand probes with the best stability and activity. Once synthesized and coated, the colloidal gold probes are buffered and an inert protein is further added in order to ensure complete stability. If properly prepared, these probes are very stable. In our laboratory, we currently store in the fridge antibody-coated probes prepared four years ago which still show the same reactivity as at the time of preparation.

We use colloidal gold probes for the determination of the affinity parameters of binding proteins for their ligands and take advantage of the changes in the visible spectrum due to the modification in the LSPR of gold occurring during the interaction. As an example, Fig. 6 shows the difference spectra recorded for colloidal gold nanoparticles coated with an anti-theophylline monoclonal antibody after interaction with increasing amounts of the ligand. The progressive decrease in extinction at the LSPR of gold probes is clearly apparent, along with the increase of extinction at longer wavelengths resulting from the peak red-shift. We had published results with this technique for proteins in our 1998 article [8] and have more recently validated the technique for high-throughput screening (HTS) with both protein and small organic molecule ligands [94]. For this application in HTS mode, we use a clinical chemistry analyzer (Cobas-mira plus) instead of a spectrophotometer [12] to record the signal. This instrument (formerly marketed by Hoffmann LaRoche, now by ABX Diagnostics) is a walk-away system capable of mixing and incubating samples and reagents in individual cuvettes and to monitor absorbance $(A)$ at

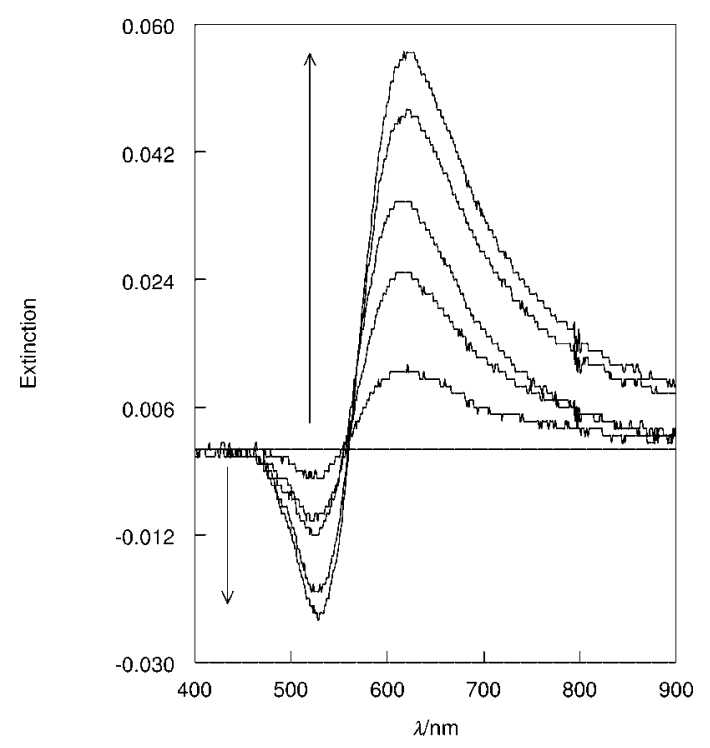

Fig. 6. Difference visible spectra recorded after interaction of colloidal gold particles in solution coated with a monoclonal anti-theophylline antibody (20 pmol) with increasing concentrations of the ligand (respectively 2.8, 5.6, 11.2, 28 and $56 \mathrm{pmol}$ ). The arrows indicate respectively the progressive decrease of extinction at the LSPR of gold and the simultaneous increase in extinction at longer wavelengths. 
a fixed wavelength according to preprogrammed conditions. Automated clinical analyzers are in wide use in clinical laboratories for the quantitative analysis of several parameters in blood and urine [95]. However, the technique should be applicable to a microtiter plate format as well. We prefer to use a Cobas-mira plus instrument among other analyzers because it is equipped with a high energy flash lamp, which increases the sensitivity of signal detection. The instrument carousel contains 72 cuvettes thermostated at $37^{\circ} \mathrm{C}$ automatically replaced according to needs, and the photometer records the $A$ in each cuvette every $25 \mathrm{sec}$ during a maximum incubation period of $20 \mathrm{~min}$. During incubation, we monitor the

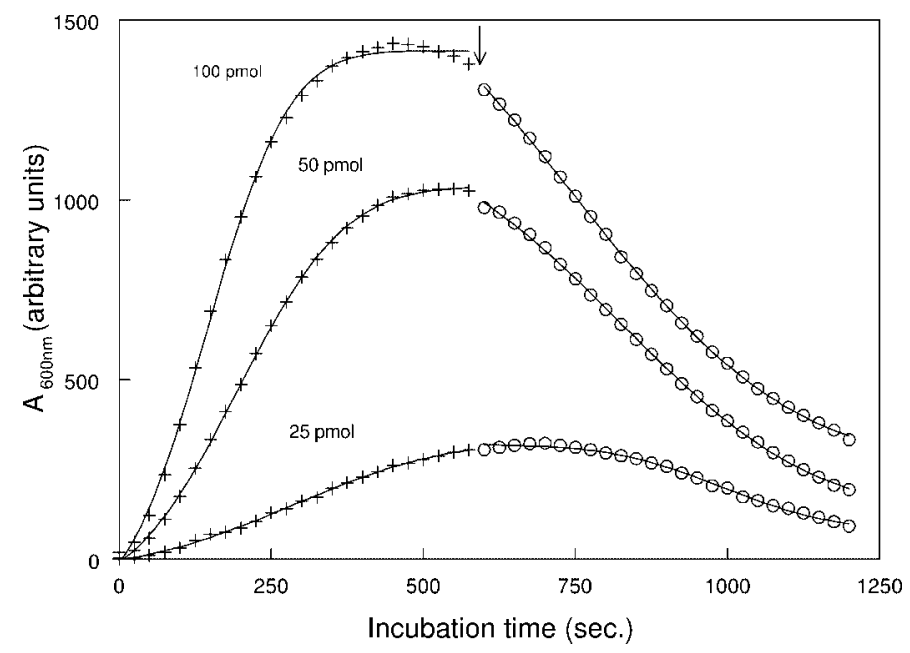

Fig. 7. Association and dissociation kinetics observed by A change measurements in the Cobas mira analyzer during interaction of colloidal gold nanoparticles coated with a specific anti-TnI monoclonal antibody (OEM Concepts, Toms River, NJ, 5 pmol) with three doses of the ligand. The dissociation (circles) is induced (arrow) by injecting an excess of ligand in the cuvette. The calculated affinity is $1.4 \times 10^{9} \mathrm{~mol}^{-1}$.

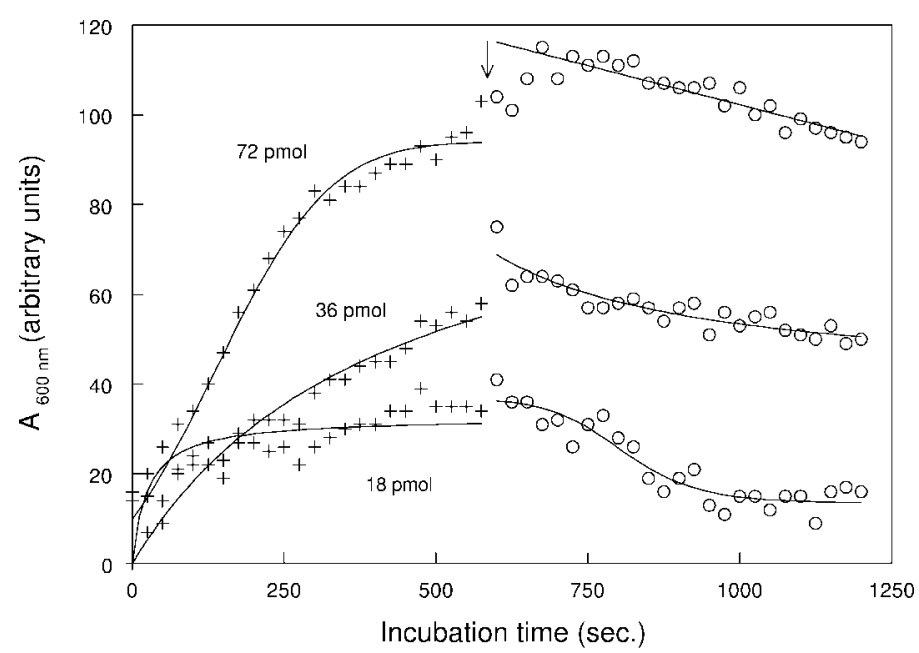

Fig. 8. Association and dissociation kinetics observed by A change measurements in the Cobas mira analyzer during interaction of colloidal gold nanoparticles coated with a specific anti-digoxin monoclonal antibody (13310, OEM Concept, Toms River, $\mathrm{NJ}, 5 \mathrm{pmol}$ ) with three doses of the ligand. The dissociation (circles) is induced (arrow) by injecting an excess of ligand in the cuvette. The calculated affinity is $1.3 \times 10^{10} \mathrm{~mol}^{-1}$. 
changes in $A_{600 \mathrm{~nm}}$ during the association and dissociation kinetics. Figures 7 and 8 present examples of such experiments with colloidal gold nanoparticles respectively coated with anti-troponin I (TnI) and anti-digoxin antibodies associating with three different doses of the respective ligand, TnI (a protein) and digoxin (a small drug). We use to induce the dissociation by the injection of a large excess of ligand into the cuvette (between 100 and 1,000 fold excess depending on the ligand). Since the SPR method with colloidal gold does not rely on particle agglutination to generate the signal $[8,12]$, the role of ligand excess in inducing the dissociation was not clear at first sight. Therefore we compared the kinetics between digoxin and a colloidal gold probe coated with an anti-digoxin antibody and after association equilibrium was reached, we injected either PBS or PBS containing a 500 fold ligand excess. The results are displayed in Fig. 9. When PBS alone was added, the equilibrium was maintained and no dissociation occurred, counter to what happened when the ligand was added in excess. As shown 15 years ago by Nygren et al. [96], the kinetics at solid-liquid interfaces obey to laws differing from those governing the interactions in true solutions. They are diffusion- rather than reaction (mass action)-limited. These authors observed that ligand dissociated from antibody immobilised on silicon wafers in presence of ligand excess, not when the solid phase was washed with PBS alone. Similarly, in particle systems, external diffusion phenomena play a major role which tend to concentrate the ligand at the particle surface and the fraction of ligand bound by the immobilised binding protein is inversely proportional to both the total ligand concentration and total binding site concentration available [97,98]. At steady-state, the total ligand concentration at the particle surface is constant and this results in a lack of dissociation, even when the medium composition is modified. When an excess of ligand is added, a new diffusion-rate situation is created which increases the ligand concentration at the particle surface. This in turns results in a decrease of the bound ligand fraction, which can explain the dissociation phenomenon observed. We have validated this method in the Cobas-mira [94] by comparing the affinity constants of 30 pairs of ligand-protein interactions (affinity range $10^{3}-10^{12} \mathrm{~mol}^{-1}$ ) obtained with our method with those obtained from other methods. The ligands considered included large and medium size proteins as well as small organic molecules. The methods used for comparison encompassed the BIAcore and saturation methods in solution including dialysis. The regression slope was 0.84 and the correlation 0.82 . Repeatability measurements indicated a variation of $10-20 \%$ for most of the binding affinities calculated by the colloidal gold SPR technique.

A second use of SPR with colloidal gold particles, the immunoassay, is a direct application of the capacity of antibody-coated probes to quantitatively sense analyte-binding $[3,8,83]$. The technique is quite sensitive and is applicable to both (poly)peptides and small ligands. Figure 10 display typical doseresponse curves for digoxin (part A) and theophylline (part B) obtained with monoclonal antibody-coated nanoparticles in immunoassays involving short incubations $\left(10 \min 37^{\circ} \mathrm{C}\right)$ performed in the Cobas-mira instrument. The reproducibility between duplicate measurements is acceptable as shown by the error bars around the data points. With our immunoassay for serum ferritin, the between run imprecision was between 2.3 and 3.8\%, depending on the dose of analyte. We compared also the results of over 100 unknown serum samples observed with the colloidal gold immunoassay and two other immunoassays (latex and chemiluminescence) of commercial origin. The regressions provided slopes close to unity with correlation coefficients ranging from 0.96 to 0.99 . The average bias was in each case close to the least detectable dose $(4.5 \mathrm{ng} / \mathrm{ml})$. Such rugged immunoassays may thus be used for clinical applications as well as in other biomedical fields where sensitive and rapid analytical techniques are required, such as in the biotechnology and pharmaceutical industry. This application can also serve in the characterization of antibodies or in epitope mapping. 


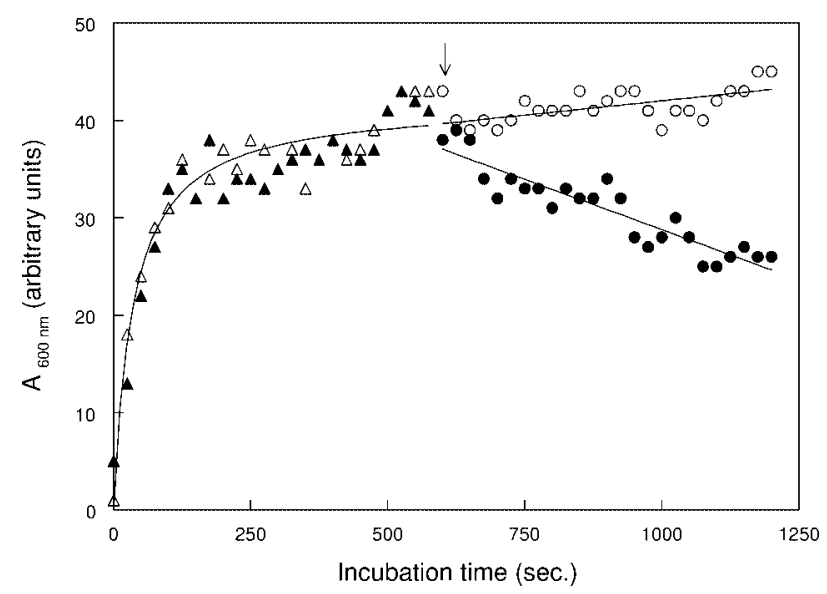

Fig. 9. Kinetics of interaction between digoxin and anti-digoxin-coated colloidal gold nanoparticles in solution. In both cases, the association occurred in the presence of the same ligand concentration (open and closed triangles). After 10 min of incubation, the same volume of either PBS (open circles) or PBS containing a 500-fold excess of digoxin (closed triangles) was added (arrow). Dissociation occurs exclusively in presence of ligand excess.
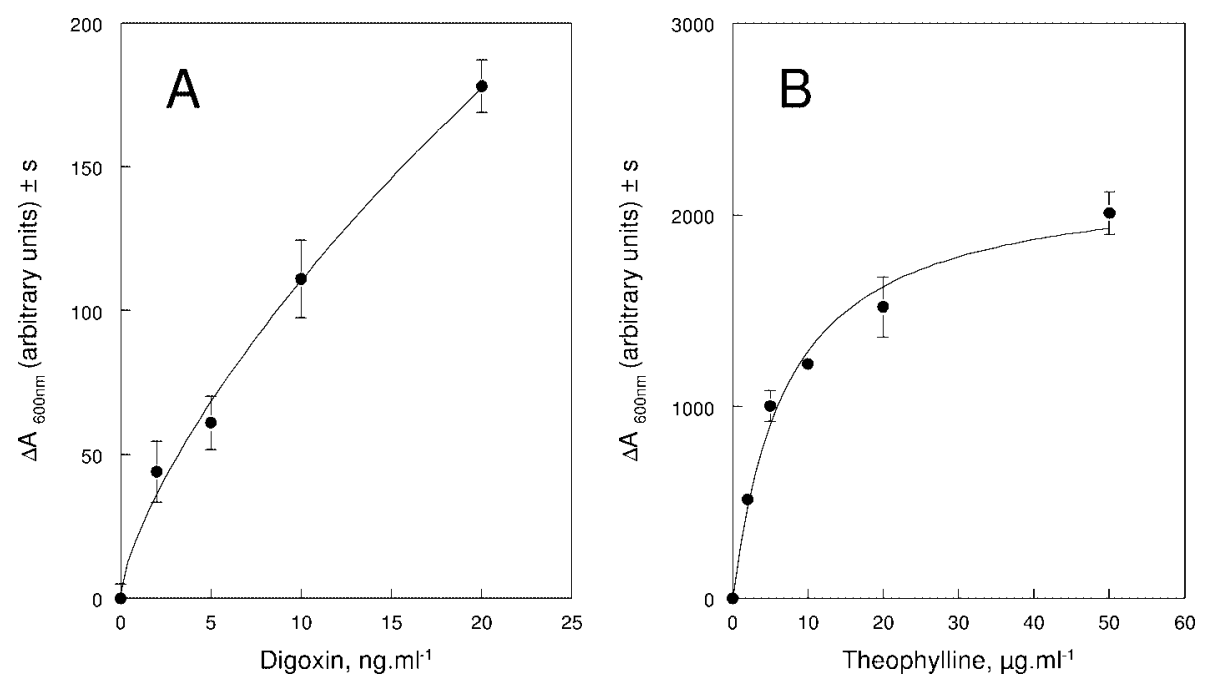

Fig. 10. Examples of dose-response curves obtained for digoxin (part A) and theophylline (part B) by application of SPR with colloidal gold particles in immunoassays. The curves are drawn from the SPR signal generated in solution by antibody-coated colloidal gold nanoparticles incubated during $10 \mathrm{~min} 37^{\circ} \mathrm{C}$ in the Cobas-mira instrument with increasing concentrations of the respective analytes. The data points are the means \pm error of independent duplicate measurements.

Finally, like SPR biosensors, SPR with colloidal gold is capable of monitoring changes in protein conformation. The technique was used as early as in 1997 to monitor the conformational changes of cytochrome $b_{562}$ [100]. In this study, the authors recorded the LSPR band shift of colloidal gold nanoparticles which occurred depending on the particle surface coverage by the protein. Depending on the LSPR band shift observed, they could detect the change in the protein conformation from a side-on to a tail-on coverage of the particles. We will further illustrate this application by another example. Human serum albumin is known [101] to experience conformational changes in alkaline conditions that are illustrated by the three-dimensional (3D) models of Fig. 11. From pH 7 (Fig. 11, top part), to pH 9 (Fig. 11, middle 

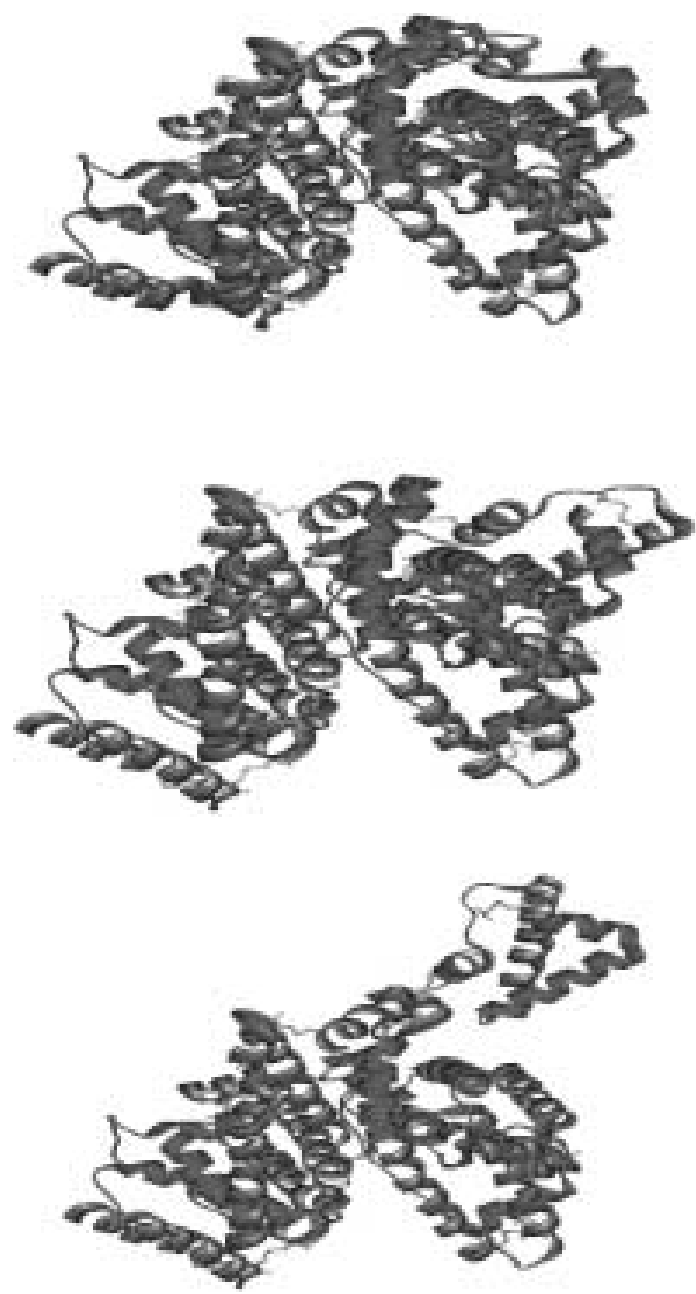

Fig. 11. 3D models of human serum albumin illustrating the conformational transitions occurring from $\mathrm{pH} 7$ (top) to $\mathrm{pH} 9$ (middle) and above $\mathrm{pH} 11$ (bottom) as a result of proton loss and disulfide bond accessibility. The model was obtained from the protein data bank (id.1bm0) [99] and was modified using the WebLab Viewer Pro v3.7 program (Accelrys Inc., Burlington, MA).

part), the protein conformation of the $\mathrm{N}$-terminal half changes dramatically due to a deprotonation [102, 103] which results in the direct accessibility to reduction of five cysteine disulfide bonds which at $\mathrm{pH} 7$ are hidden in the structure [101]. This conformational transition is known as the neutral or $\mathrm{N}$ to $\mathrm{B}$ transition and is maximal at $\mathrm{pH} 9$. At higher $\mathrm{pH}$ (Fig. 11, bottom part), a second transition occurs between pH 11.3 and 11.6 which is known as the alkaline transition [102]. This transition makes a further cysteine disulfide bond accessible by unfolding [101,102]. In order to follow these two transitions, we monitored the changes in extinction occurring at the LSPR of colloidal gold nanoparticles at increasing $\mathrm{pH}$ values during an incubation of $10 \mathrm{~min}$. As the results displayed in Fig. 12 indicate, both conformational changes are reported by two maxima in the titration curve at the expected $\mathrm{pH}$ values.

As these examples show, the technique of SPR measurement with colloidal gold in solution has many possible applications in the field of biomedical sciences. The technique offers the advantage of requiring cheap reagents and of being applicable to easily accessible instrumentation. 


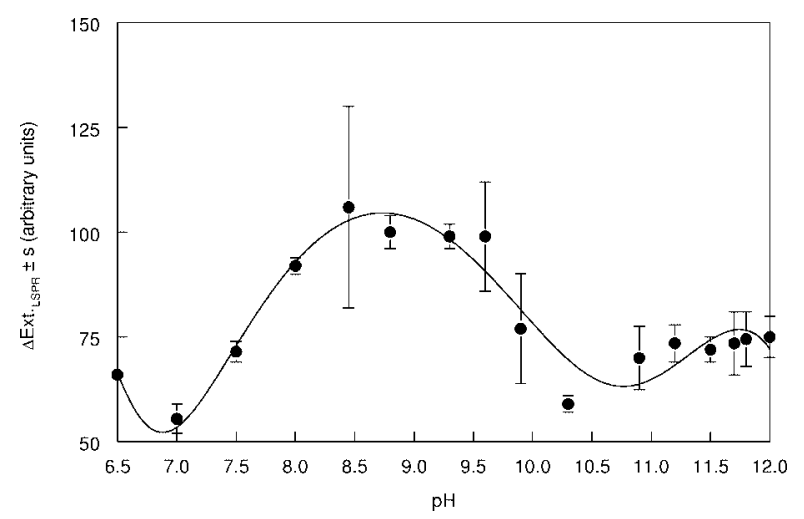

Fig. 12. Measurement of conformational transitions of human serum albumin between $\mathrm{pH} 7$ and 12 by recording the changes in extinction at the LSPR band of colloidal gold nanoparticles coated with the protein in buffered solutions. The buffers used are $0.1 \mathrm{M}$ phosphate $0.15 \mathrm{M} \mathrm{NaCl}(\mathrm{pH} 7$ and 7.5$)$ and $0.1 \mathrm{M}$ borate $0.15 \mathrm{M} \mathrm{NaCl}$ for higher pHs. Data are averages \pm error of independent duplicate measurements. The two maxima at $\mathrm{pH} 9$ and 11-11.5 report the $\mathrm{N}-\mathrm{B}$ and alkaline transitions of albumin conformation, respectively (see text for details).

\section{Conclusions and future prospects}

The SPR technique is rather a recent introduction in the arsenal of means applicable to analysis and characterization in the field of biomedical sciences. Despite its relative youth, the many applications published in the literature which involve both SPR with biosensors and with colloidal nanoparticles in solution, demonstrate in sufficience the robustness of the spectroscopic concept and its practical usefulness.

Recent developments are worth mentioning, that will undoubtedly increase the sensitivity, the specificity and the applicability of the technique. The recent integration of SPR and electrochemistry through the combination of SPR biosensors with conductive polymer films is certainly of prime interest [104106]. In a previous paper [3], we had already stressed the advantages that could be gained by such composite materials of colloidal gold nanoparticles [107]. Similarly, the use of $\mathrm{Ag}-\mathrm{Au}$ alloy nanoparticles recently synthesized $[108,109]$ with distinct optical properties may allow to improve the detection of biological interactions or phenomena by noble metal nanoparticle LSPR. The application of inductively coupled plasma mass spectrometry as the detection system in a colloidal gold nanoparticle immunoassay [110] allows to improve the specificity of such non isotopic immunoassay system. Finally, recent developments have shown that the SPR technique was applicable not only to biomolecular interaction systems, but also to interactions involving synthetic receptors like ionophores and imprinted polymers [2]. The use of ionophores as the receptor on the sensor allows the quantitative and selective detection of ionic species [111], whilst the use of imprinted polymers permits the replacement of antibodies for the quantitative and specific detection of small molecules [112].

The exponential development applications of SPR in biomedical sciences to which we assist since the early days of its inception warrants undoubtedly further updates in the forthcoming future.

\section{References}

[1] M. Malmqvist, BIACORE: an affinity biosensor system for characterization of biomolecular interactions, Biochem. Soc. Trans. 27 (1999), 335-340.

[2] P. Englebienne, Immune and Receptor Assays in Theory and Practice, CRC Press, Florida, 2000. 
[3] P. Englebienne, Synthetic materials capable of reporting biomolecular recognition events by chromic transition, J. Mater. Chem. 9 (1999), 1043-1054.

[4] H.O.A. Hill and J.J. Davis, Biosensors: past, present and future, Biochem. Soc. Trans. 27 (1999), 331-335.

[5] K. Haupt and K. Mosbach, Molecularly imprinted polymers in chemical and biological sensing, Biochem. Soc. Trans. 27 (1999), 344-350.

[6] M. Adamczyk, D.D. Johnson, P.G. Mattingly, J.A. Moore and Y. Pan, Immunoassay reagents for thyroid testing. 3. Determination of the solution binding affinities of a T4 monoclonal antibody Fab fragment for a library of thyroxine analogs using surface plasmon resonance, Bioconjugate Chem. 9 (1998), 23-32.

[7] J. Rademann and G. Jung, Integrating combinatorial synthesis and bioassays, Science 287 (2000), 1947-1948.

[8] P. Englebienne, Use of colloidal gold surface plasmon resonance peak shift to infer affinity constants from the interaction between protein antigens and antibodies specific for single or multiple epitopes, Analyst 123 (1998), 1599-1603.

[9] L.A. Lyon, M.D. Musick and M.J. Nathan, Colloidal Au-enhanced surface plasmon resonance immunosensing, Anal. Chem. 70 (1998), 5177-5183.

[10] M. Gluodenis, C. Manley and C.A. Foss, Jr., In situ monitoring of the change in extinction of stabilized nanoscopic gold particles in contact with aqueous phenol solutions, Anal. Chem. 71 (1999), 4554-4558.

[11] S. Schultz, D.R. Smith, J.J. Mock and D.A. Schultz, Single-target molecule detection with nonbleaching multicolor optical immunolabels, Proc. Natl. Acad. Sci. USA 97 (2000), 996-1001.

[12] N. Nath and A. Chilkoti, A colorimetric gold nanoparticle sensor to interrogate biomolecular interactions in real time on a surface, Anal. Chem. 74 (2002), 504-509.

[13] A.G. Frutos and R.M. Corn, SPR of ultrathin organic films, Anal. Chem. 70 (1998), 449A-455A.

[14] K. Kurihara and K. Suzuki, Theoretical understanding of an absorption-based surface plasmon resonance sensor based on Kretchmann's theory, Anal. Chem. 74 (2002), 696-701.

[15] M. Malmqvist, Real-time biospecific interaction analysis for the direct measurement of antibody-antigen interactions, in: Immunotechnology, J.P. Gosling and D.J. Reen, eds, Portland Press, London, 1993, pp. 61-75.

[16] W.D. Wilson, Analyzing biomolecular interactions, Science 295 (2002), 2103-2105.

[17] S. Boussaad, J. Pean and N.J. Tao, High-resolution multiwavelength surface plasmon resonance spectroscopy for probing conformational and electronic changes in redox proteins, Anal. Chem. 72 (2000), 222-226.

[18] S. Wang, S. Boussaad, S. Wong and N.J. Tao, High-sensitivity stark spectroscopy obtained by surface plasmon resonance measurement, Anal. Chem. 72 (2000), 4003-4008.

[19] L.S. Jung, C.T. Campbell, T.M. Chinowsky, M.N. Mar and S.S. Yee, Quantitative interpretation of the response of surface plasmon resonance sensors to adsorbed films, Langmuir 14 (1998), 5636-5648.

[20] T. Zacher and E. Wischerhoff, Real-time two-wavelength surface plasmon resonance as a tool for the vertical resolution of binding processes in biosensing hydrogels, Langmuir 18 (2002), 1748-1759.

[21] X. Caide and S.F. Sui, Numerical simulations of surface plasmon resonance system for monitoring DNA hybridization and detecting protein-lipid film interactions, Eur. Biophys. J. 28 (1999), 151-157.

[22] J.C. O'Brien, V.W. Jones, M.D. Poter, C.L. Mosher and E. Henderson, Immunosensing platforms using spontaneously adsorbed antibody fragments on gold, Anal. Chem. 72 (2000), 703-710.

[23] J. Lahiri, L. Isaacs, J. Tien and G.M. Whitesides, A strategy for the generation of surfaces presenting ligands for studies of binding based on an active ester as a common reactive intermediate: a surface plasmon resonance study, Anal. Chem. 71 (1999), 777-790.

[24] T. Yoshida, M. Sato, T. Ozawa and Y. Umezawa, An SPR-based screening method for agonist selectivity for insulin signaling pathways based on the binding of phosphotyrosine to its specific binding protein, Anal. Chem. 72 (2000), 6-11.

[25] A.J. Thiel, A.G. Frutos, C.E. Jordan, R.M. Corn and L.M. Smith, In situ surface plasmon resonance imaging detection of DNA hybridization to oligonucleotide arrays on gold surfaces, Anal. Chem. 69 (1997), 4948-4956.

[26] C.E. Jordan, A.G. Frutos, A.J. Thiel and R.M. Corn, Surface plasmon resonance imaging measurements of DNA hybridization adsorption and streptavidin/DNA multilayer formation at chemically modified gold surfaces, Anal. Chem. 69 (1997), 4939-4947.

[27] M. Burgener, M. Sänger and U. Candrian, Synthesis of a stable and specific surface plasmon resonance biosensor surface employing covalently immobilized peptide nucleic acids, Bioconjugate Chem. 11 (2000), 749-754.

[28] M.M. Morelock, R.H. Ingraham, R. Betageri and S. Jakes, Determination of receptor-ligand kinetic and equilibrium binding constants using surface plasmon resonance: application to the lck SH2 domain and phosphotyrosyl peptides, J. Med. Chem. 38 (1995), 1309-1318.

[29] M. Adamczyk, P.G. Mattingly, K. Shreder and Z. Yu, Surface plasmon resonance (SPR) as a tool for antibody conjugate analysis, Bioconjugate Chem. 10 (1999), 1032-1037.

[30] E.M. Phizicky and S. Fields, Protein-protein interactions: methods for detection and analysis, Microbiol. Rev. 59 (1995), 94-123. 
[31] K. Andersson, M. Hämäläinen and M. Malmqvist, Identification and optimization of regeneration conditions for affinitybased biosensor assays. A multivariate cocktail approach, Anal. Chem. 71 (1999), 2474-2481.

[32] C.E.H. Berger, T.A.M. Beumer, R.P.H. Kooyman and J. Greve, Surface plasmon resonance multisensing, Anal. Chem. 70 (1998), 703-706.

[33] M.L. Shank-Retzlaff and S.G. Sligar, Analyte gradient-surface plasmon resonance: a one-step method for determining kinetic rates and macromolecular binding affinities, Anal. Chem. 72 (2000), 4212-4220.

[34] B. Cheskis and L.P. Freedman, Modulation of nuclear receptor interactions by ligands: kinetic analysis using surface plasmon resonance, Biochem. 35 (1996), 3309-3318.

[35] M. Adamczyk, P.G. Mattingly, K. Shreder and S. Yu, Surface plasmon resonance (SPR) as a tool for antibody conjugate analysis, Bioconjugate Chem. 10 (1999), 1032-1037.

[36] M.H.V. Van Regenmortel and L. Choulier, Recognition of peptides by antibodies and investigations of affinity using biosensor technology, Comb. Chem. High throughput Screen 4 (2001), 385-395.

[37] Y. Iwasaki, T. Horiuchi and O. Niwa, Detection of electrochemical enzymatic reactions by surface plasmon resonance measurement, Anal. Chem. 73 (2001), 1595-1598.

[38] E. Kai, S. Sawata, K. Ikebukuro, T. Iida, T. Honda and I. Karube, Detection of PCR products in solution using surface plasmon resonance, Anal. Chem. 71 (1999), 796-800.

[39] B. Johne, Epitope mapping by surface plasmon resonance in the BIAcore, Mol. Biotechnol. 9 (1998), 65-71.

[40] L. Laricchia-Robbio, S. Balzan, S. Ghione, U. Montali and R.P. Revoltella, Detection of digitalis compounds using surface plasmon resonance-based biosensor, Biosens. Bioelectron. 13 (1998), 1055-1060.

[41] W. Mullett, E.P. Lai and J.M. Yeung, Immunoassay of fumonisins by a surface plasmon resonance biosensor, Anal. Biochem. 258 (1998), 161-167.

[42] W.M. Mullett, E.P.C. Lai, J.M. Yeung, Surface plasmon resonance-based immunoassays, Methods 22 (2000), 77-91.

[43] K. Gaus and E.A.H. Hall, Detection of oxidized low-density lipoproteins using surface plasmon resonance, Anal. Chem. 71 (1999), 2459-2467.

[44] E. Danielan, A. Karlen, R. Karlsson, S. Winiwarter, A. Hansson, S. Löfas, H. Lennernäs and M. Hämäläinen, SPR biosensor studies of the direct interaction between 27 drugs and a liposome surface: correlation with fraction absorbed in humans, J. Med. Chem. 43 (2000), 2083-2086.

[45] A. Frostell-Karlsson, A. Remaeus, H. Roos, K. Andersson, P. Borg, M. Hämäläinen and R. Karlsson, Biosensor analysis of the interaction between immobilized human serum albumin and drug compounds for prediction of human serum albumin binding levels, J. Med. Chem. 43 (2000), 1986-1992.

[46] M.H. Van Regenmortel, Analysing structure-function relationships, Cell. Mol. Life Sci. 58 (2001), 794-800.

[47] M. Adamczyk, J.C. Gebler, A.H. Gunasekera, P.G. Mattingly and Y. Pan, Immunoassay reagents for thyroid testing. 2. Binding properties and energetic parameters of a $T_{4}$ monoclonal antibody and its Fab fragment with a library of thyroxine analog biosensors using surface plasmon resonance, Bioconjugate Chem. 8 (1997), 133-145.

[48] E. Kaganer, R. Pogreb, D. Davidov and I. Willner, Surface plasmon resonance characterization of photoswitchable antigen-antibody interactions, Langmuir 15 (1999), 3920-3923.

[49] C.A. Lipschultz, Y. Li and S. Smith-Gill, Experimental design for analysis of complex kinetics using surface plasmon resonance, Methods 20 (2000), 310-318.

[50] E. De Genst, D. Areskoug, K. Decanniere, S. Muyldermans and K. Andersson, Kinetic and affinity predictions of a protein-protein interaction using multivariate experimental design, J. Biol. Chem. (June 4, 2002), 10.174/jbc M202359200.

[51] H. Sota, Y. Hasegawa and M. Iwakura, Detection of conformational changes in an immobilized protein using surface plasmon resonance, Anal. Chem. 70 (1998), 2019-2024.

[52] T. Mannen, S. Yamaguchi, J. Honda, S. Sugimoto, A. Kitayama and T. Nagamune, Observation of charge state and conformational change in immobilized protein using surface plasmon resonance sensor, Anal. Biochem. 293 (2001), $185-193$.

[53] R.W. Nelson, J.R. Krone and O. Jansson, Surface plasmon resonance biomolecular interaction analysis mass spectrometry. 1. Chip-based analysis, Anal. Chem. 69 (1997), 4363-4368.

[54] S. Lin, S. Long, S.M. Ramirez, R.J. Cotter and A.S. Woods, Characterization of the "helix clamp" motif of HIV-1 reverse transcriptase using MALDI-TOF MS and surface plasmon resonance, Anal. Chem. 72 (2000), 2635-2640.

[55] S. Owega, E.P.C. Lai and D.O. Bawagan, Surface plasmon resonance-laser desorption/ionization-time-of-flight mass spectrometry, Anal. Chem. 70 (1998), 2360-2365.

[56] M. Schuerenberg, C. Luebbert, H. Eickhoff, M. Kalkum, H. Lehrach and E. Nordhoff, Prestructured MALDI-MS sample supports, Anal. Chem. 72 (2000), 3436-3442.

[57] T. Johnson, J. Bergquist, R. Ekman, E. Nordhoff, M. Schürenberg, K.-D. Klöppel, M. Müller, H. Lehrach and J. Gobom, A CE-MALDI interface based on the use of prestructured sample supports, Anal. Chem. 73 (2001), 1670-1675.

[58] J.J. Gilligan, P. Schuck and A.L. Yergey, Mass spectrometry after capture and small-volume elution of analyte from a surface plasmon resonance biosensor, Anal. Chem. 74 (2002), 2041-2047. 
[59] Z. Salamon and G. Tollin, Plasmon resonance spectroscopy: probing molecular interactions at surfaces and interfaces, Spectroscopy 15 (2001), 161-175.

[60] C.L. Baird and D.G. Myszka, Current and emerging commercial optical biosensors, J. Mol. Recognit. 14 (2001), 261268.

[61] T. Wink, S.J. van Zuilen, A. Bult and W.P. van Bennekom, Liposome-mediated enhancement of the sensitivity in immunoassays of proteins and peptides in surface plasmon resonance spectrometry, Anal. Chem. 70 (1998), 827-832.

[62] M. Adamczyk, J.A. Moore and Z. Yu, Application of surface plasmon resonance toward studies of low-molecular weight antigen-antibody binding interactions, Methods 20 (2000), 319-328.

[63] M. Strandh, B. Persson, H. Roos and S. Ohlson, Studies of interactions with weak affinities and low-molecular-weight compounds using surface plasmon resonance technology, J. Mol. Recognit. 11 (1998), 188-190.

[64] J.E. Gestwicki, H.V. Hsieh and J.B. Pitner, Using receptor conformational change to detect low molecular weight analytes by surface plasmon resonance, Anal. Chem. 73 (2001), 5732-5737.

[65] L. He, M.D. Musick, S.R. Nicewarner, F.G. Salinas, S.J. Benkovic, M.J. Natan and C.D. Keating, Colloidal Au-enhanced surface plasmon resonance for ultrasensitive detection of DNA hybridization, J. Am. Chem. Soc. 122 (2000), 9071-9077.

[66] L.A. Lyon, D.J. Pena and M.J. Natan, Surface plasmon resonance of Au colloid-modified Au films: particle size dependence, J. Phys. Chem. B 103 (1999), 5826-5831.

[67] E. Hutter, S. Cha, J.-F. Liu, J. Park, J. Yi, J.H. Fendler and D. Roy, Role of substrate metal in gold nanoparticle enhanced surface plasmon resonance imaging, J. Phys. Chem. B 105 (2001), 8-12.

[68] M.L. Yarmush, D.B. Patankar and D.M. Yarmush, An analysis of transport resistances in the operation of BIAcore; implications for kinetic studies of biospecific interactions, Mol. Immunol. 33 (1996), 1203-1214.

[69] L. Nieba, A. Krebber and A. Pluckthun, Competition BIAcore for measuring true affinities: large differences from values determined from binding kinetics, Anal. Biochem. 234 (1996), 155-165.

[70] B.P. Nelson, T.E. Grimsrud, M.R. Liles, R.M. Goodman and R.M. Corn, Surface plasmon resonance imaging measurement of DNA and RNA hybridization adsorption onto DNA microarrays, Anal. Chem. 73 (2001), 1-7.

[71] M.D. Malinsky, K.L. Kelly, G.C. Schatz and R.P. Van Duyne, Nanosphere lithography: effect of substrate on the localized surface plasmon resonance spectrum of silver nanoparticles, J. Phys. Chem. B 105 (2001), 2343-2350.

[72] C.A. Foss Jr, G.L. Hornyak, J.A. Stockert and C.R. Martin, Optical properties of composite membranes containing arrays of nanoscopic gold cylinders, J. Phys. Chem. 96 (1992), 7497-7499.

[73] C.A. Foss Jr, G.L. Hornyak, J.A. Stockert and C.R. Martin, Template-synthesized nanoscopic gold particles: optical spectra and the effects of particle size and shape, J. Phys. Chem. 98 (1994), 2963-2971.

[74] J.H. Leuvering, P.J. Thal, M. van der Waart and A.H. Schuurs, Sol particle immunoassay (SPIA), J. Immunoassay 1 (1980), 77-91.

[75] J.H. Leuvering, P.J. Thal, M. van der Waart and A.H. Schuurs, A sol particle agglutination assay for human chorionic gonadotrophin, J. Immunol. Methods 45 (1981), 183-194.

[76] J.H. Leuvering, B.C. Goverde, P.J. Thal and A.H. Schuurs, A homogeneous sol particle immunoassay for human chorionic gonadotrophin using monoclonal antibodies, J. Immunol. Methods 60 (1983), 9-23.

[77] J.H. Leuvering, P.J. Thal and A.H. Schuurs, Optimization of a sandwich sol particle immunoassay for human chorionic gonadotrophin, J. Immunol. Methods 62 (1983), 175-184.

[78] J.H. Leuvering, P.J. Thal, D.D. White and A.H. Schuurs, A homogeneous sol particle immunoassay for total oestrogens in urine and serum samples, J. Immunol. Methods 62 (1983), 163-174.

[79] T.C. Gribnau, J.H. Leuvering and H. van Hell, Particle-labelled immunoassays: a review, J. Chromatogr. 376 (1986), $175-189$.

[80] R. van Erp, T.C. Gribnau, A.P. van Sommeren and H.P. Bloemers, Application of a sol particle immunoassay to the determination of affinity constants of monoclonal antibodies, J. Immunoassay 12 (1991), 425-443.

[81] R. Elghanian, J.J. Storhoff, R.C. Mucic, R.L. Letsinger and C.A. Mirkin, Selective colorimetric detection of polynucleotides based on the distance-dependent optical properties of gold nanoparticles, Science 277 (1997), 1078-1081.

[82] J.J. Storhoff, R. Elghanian, R.C. Mucic, C.A. Mirkin and R.L. Letsinger, One-pot colorimetric differentiation of polynucleotides with single base imperfections using gold nanoparticle probes, J. Am. Chem. Soc. 120 (1998), 1959-1964.

[83] P. Englebienne, A. Van Hoonacker and J. Valsamis, Rapid homogeneous immunoassay for human ferritin in the Cobas mira using colloidal gold as the reporter reagent, Clin. Chem. 46 (2000), 2000-2003.

[84] S. Underwood and P. Mulvaney, Effect of the solution refractive index on the color of gold colloids, Langmuir 10 (1994), $3427-3430$.

[85] G. Chumanov, K. Sokolov, B.W. Gregory and T.M. Cotton, Colloidal metal films as a substrate for surface-enhanced spectroscopy, J. Phys. Chem. 99 (1995), 9466-9471.

[86] T.R. Jensen, M.L. Duval, K.L. Kelly, A.A. Lazarides, G.C. Schatz and R.P. Van Duyne, Nanosphere lithography: effect of the external dielectric medium on the surface plasmon resonance spectrum of a periodic array of silver nanoparticles, J. Phys. Chem. B 103 (1999), 9846-9853. 
[87] T.R. Jensen, M.D. Malinsky, C.L. Haynes and R.P. Van Duyne, Nanosphere lithography: tunable localized surface plasmon resonance spectra of silver nanoparticles, J. Phys. Chem. B 104 (2000), 10 549-10 556.

[88] M.D. Malinsky, K.L. Kelly, G.C. Schatz and R.P. Van Duyne, Chain length dependence and sensing capabilities of the localized surface plasmon resonance of silver nanoparticles chemically modified with alkanethiol self-assembled monolayers, J. Am. Chem. Soc. 123 (2001), 1471-1482.

[89] C. De Roe, P.J. Courtoy and P. Baudhuin, A model of protein-colloidal gold interactions, J. Histochem. Cytochem. 35 (1987), 1191-1198.

[90] E. Elliott and C. Dennison, Analysis of colloidal gold probes by isoelectric focusing in agarose gels, Anal. Biochem. 186 (1990), 53-59.

[91] W.D. Geoghegan, Immunoassays at the microscopic level: solid-phase colloidal gold methods, J. Clin. Immunoassay 11 (1988), 11-23.

[92] W.D. Geoghegan, The effect of three variables on adsorption of rabbit IgG to colloidal gold, J. Histochem. Cytochem. 36 (1988), 401-407.

[93] S.R. Simmons and R.M. Albrecht, Probe size and bound label conformation in colloidal gold-ligand labels and gold immunolabels, Scanning Microscopy 3 (Suppl.) (1989), 27-34.

[94] P. Englebienne, A. Van Hoonacker and M. Verhas, High-throughput screening using the surface plasmon resonance effect of colloidal gold nanoparticles, Analyst 126 (2001), 1645-1651.

[95] L. Schoeff, Clinical chemistry instrumentation (general chemistry analyzers), Anal. Chem. 69 (1997), 201R-203R.

[96] H. Nygren, M. Werthen and M. Stenberg, Kinetics of antibody binding to solid-phase-immobilised antigen. Effect of diffusion rate limitation and steric interaction, J. Immunol. Methods 101 (1987), 63-71.

[97] M. Stenberg and L. Stilbert, External diffusion in solid-phase immunoassays, J. Theor. Biol. 120 (1986), 129-140.

[98] M. Stenberg, M. Werthen, S. Theander and H. Nygren, A diffusion limited reaction theory for microtiter plate assay, J. Immunol. Methods 112 (1988), 23-29.

[99] S. Sugio, A. Kashima, S. Mochizuki, M. Noda and K. Kobayashi, Crystal structure of human serum albumin at $2.5 \AA$ resolution, Protein Eng. 12 (1999), 439-446.

[100] H.S. Zhou, S. Aoki, I. Honma, M. Hirasawa, T. Nagamune and H. Komiyama, Conformational change of protein cytochrome b-562 adsorbed on colloidal gold particles; absorption band shift, Chem. Commun. (1997), 605-606.

[101] T. Peeters, All about Albumin, Academic Press, California, 1996.

[102] U. Kragh-Hansen, Structure and ligand binding properties of human serum albumin, Ph.D. Dissertation, University of Aarhus, 1989.

[103] B. Honoré, Conformational changes in human serum albumin induced by ligand binding, Acta Pharmacol. Toxicol. 66 (Suppl. II) (1990), 1-26.

[104] X. Kang, Y. Jin, G. Chen and S. Dong, In situ analysis of electropolymerization of aniline by combined electrochemistry and surface plasmon resonance, Langmuir 18 (2002), 1713-1718.

[105] O.A. Raitman, E. Katz, A.F. Buckmann and I. Willner, Integration of polyaniline/poly(acrylic acid) films and redox enzymes on electrode supports: an in situ electrochemical/surface plasmon resonance study of the bioelectrocatalyzed oxidation of glucose or lactate in the integrated bioelectrocatalytic systems, J. Am. Chem. Soc. 124 (2002), 6487-6496.

[106] P. Guedon, T. Livache, F. Martin, F. Lesbre, A. Roget, G. Bidan and Y. Levy, Characterization and optimization of a real-time, parallel, label-free, polypyrrole-based DNA sensor by surface plasmon resonance imaging, Anal. Chem. 72 (2002), 6003-6009.

[107] T.K. Sarma, D. Chowdhury, A. Paul and A. Chattopadhyay, Synthesis of Au nanoparticles-conductive polyaniline composite using $\mathrm{H}_{2} \mathrm{O}_{2}$ as oxidizing as well as reducing agent, Chem. Commun. (2002), 1048-1049.

[108] L. Lu, H. Wang, Y. Zhou, S. Xi, H. Zhang, J. Hu and B. Zhao, Seed-mediated growth of large, monodisperse core-shell gold-silver nanoparticles with Ag-like optical properties, Chem. Commun. (2002), 144-145.

[109] I. Lee, S.W. Han and K. Kim, Production of Au-Ag alloy nanoparticles by laser ablation of bulk alloys, Chem. Commun. (2002), 1782-1783.

[110] C. Zhang, Z. Zhang, B. Yu, J. Shi and X. Zhang, Application of the biological conjugate between antibody and colloid Au nanoparticles as analyte to inductively coupled plasma mass spectrometry, Anal. Chem. 74 (2002), 96-99.

[111] S. Nishimura, T. Yoshidome, W. Kyuutoku, M. Mitsushio and M. Higo, Characteristics of a surface plasmon resonance sensor combined with a poly(vinyl chloride) film-based ionophore technique for metal ion analyses, Anal. Sci. 18 (2002), $267-271$.

[112] A. Kugimiya and T. Takeuchi, Surface plasmon resonance sensor using molecularly imprinted polymer for detection of sialic acid, Biosens. Bioelectron. 16 (2001), 1059-1062. 


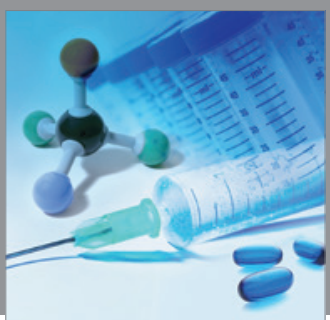

International Journal of

Medicinal Chemistry

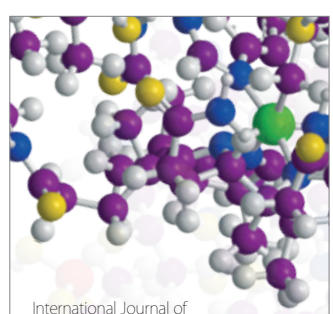

Carbohydrate Chemistry

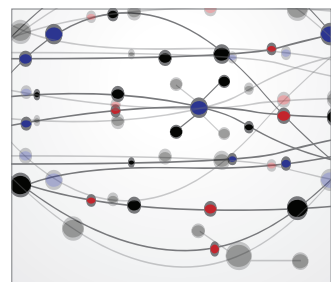

The Scientific World Journal
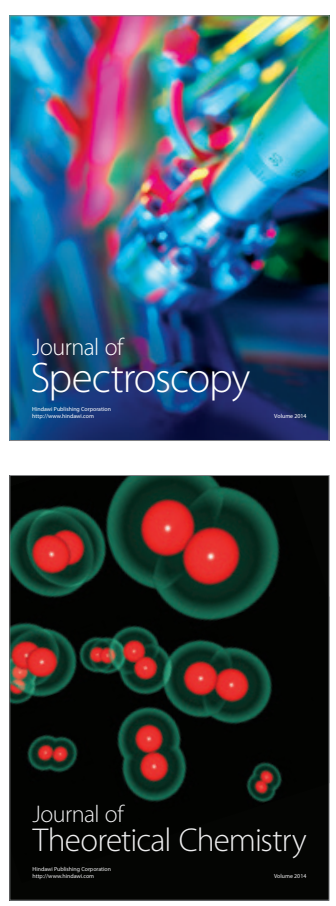
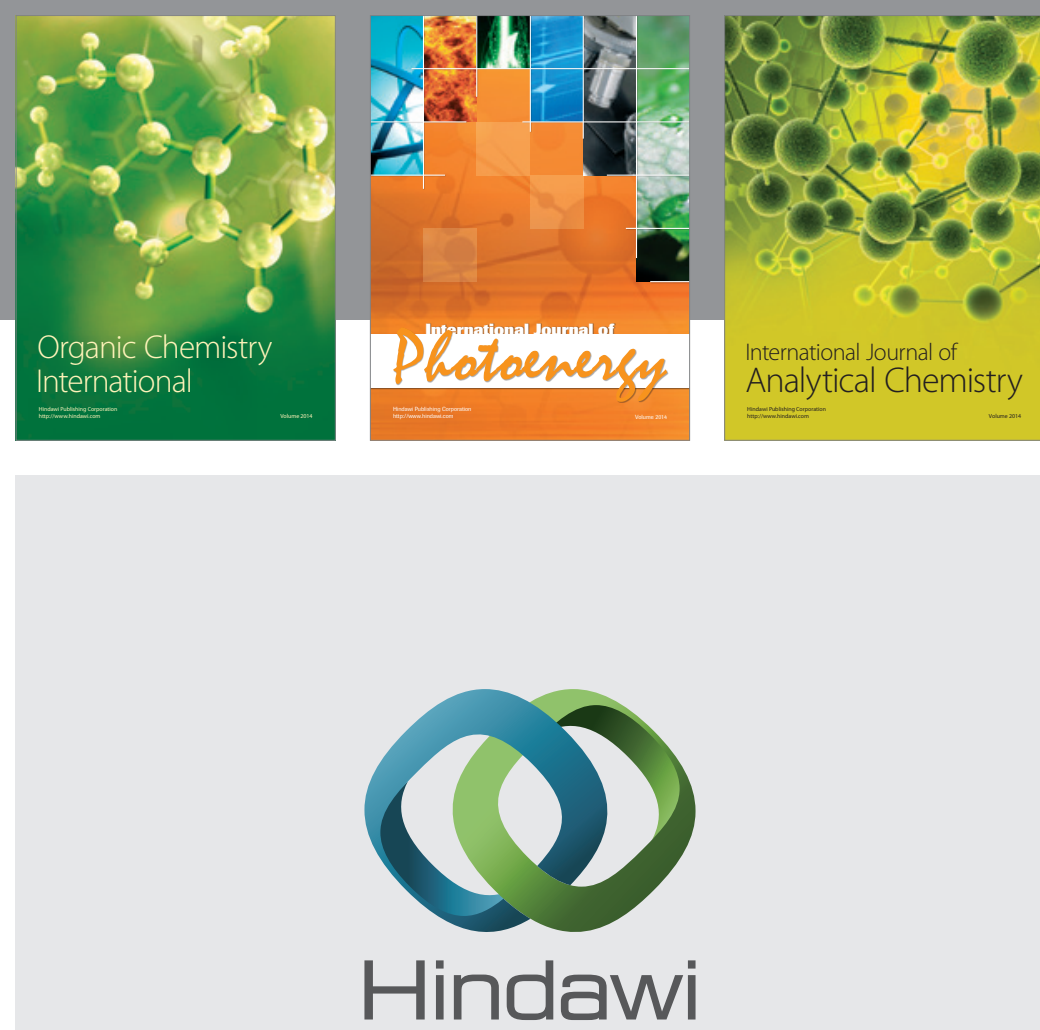

Submit your manuscripts at

http://www.hindawi.com
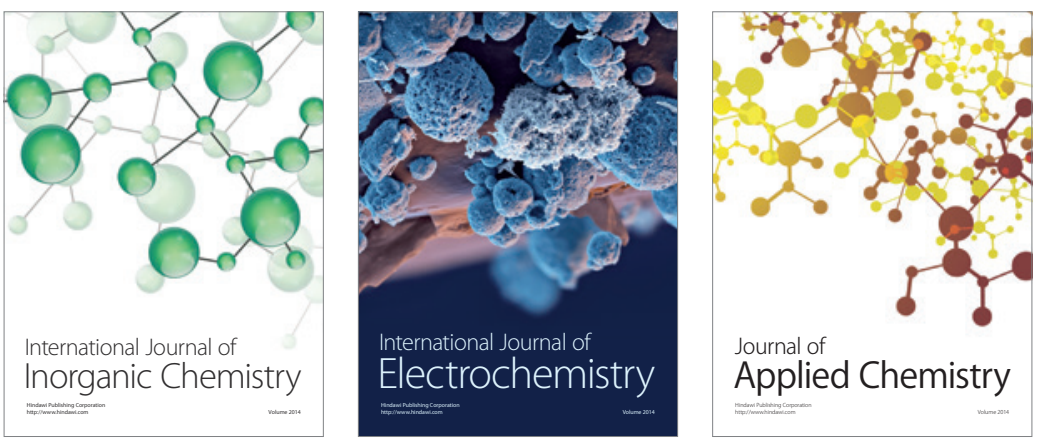

Journal of

Applied Chemistry
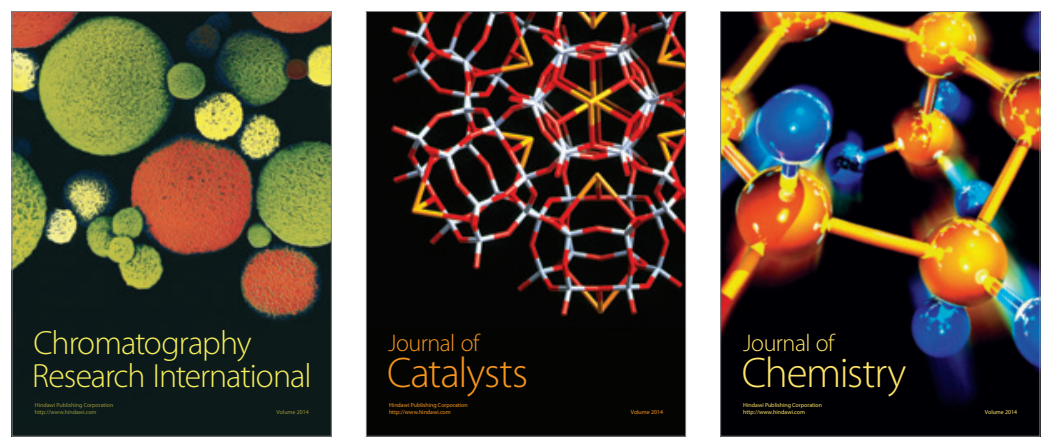
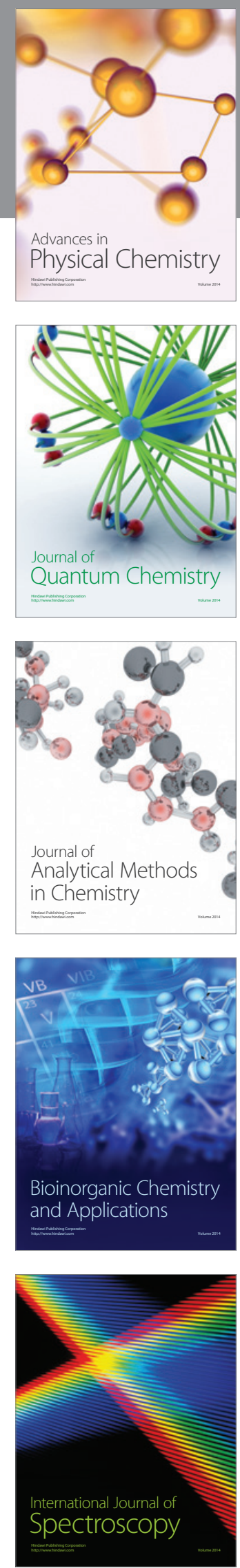